LXIX.-On some Derivatives of Anthraquinone.

By A. G. Perkin and W. H. Perkin, Jun., Ph.D.

Is a previous paper on this subject, which we had the honour of communicating to the Society some time since (Trans., 1885, 47, 679), we described a series of experiments on the products of the destructive distilation of sodium anthraquinonemonosulphonate.

This salt, when heated in an iron tube, yielded a brownish-red distillate, which on examination was found to contain metahydroxyanthraquinone, anthraquinone, and a peculiar red substance, which after purification by recrystallisation gave numbers agreeing with the formula $\mathrm{C}_{28} \mathrm{H}_{14} \mathrm{O}_{6}$; it is nearly insoluble in all the usual solvents, and, curiously enough, in alkalis also.

On oxidation with chromic acid, it yields a white crystalline substance of the formula $\mathrm{C}_{14} \mathrm{H}_{6} \mathrm{O}_{4}$, and when distilled with zinc-dust anthracene is produced, proving the substance to be an anthracenederivative. The remarkable character of this decomposition of sodium anthraquinonemonosulphonate, has led us to continue our experiments, with a view to obtain some clne as to the constitution of the compound $\mathrm{C}_{28} \mathrm{H}_{14} \mathrm{O}_{6}$. The extreme difficulty, however, of obtaining it in any quantity, owing to the tediousness of its preparation and purification, has prevented us from making as thorough an examination of the subject as we could have wished. We hope at some future date to be able to complete these experiments, and to establish without doubt the constitution of these derivatives.

Before proceeding with the examination of the red substance $\mathrm{C}_{28} \mathrm{H}_{14} \mathrm{O}_{6}$, we thought it advisable to again analyse it, in order that there might be no doubt as to its formula. A quantity was therefore prepared and very carefully purified by repeated recrystallisations from glacial acetic acid. The pure substance was thus obtained as an orange, satiny, crystalline mass, which after careful drying at 110$120^{\circ}$ gave the following results on analysis:- 
0.1609 gram substance gave 0.0495 gram $\mathrm{H}_{2} \mathrm{O}$ and 0.4450 gram $\mathrm{CO}_{2}$.

\begin{tabular}{|c|c|c|}
\hline C....... & $\begin{array}{l}\text { Theory. } \\
\mathrm{C}_{28} \mathrm{H}_{14} \mathrm{O}_{6} \text {. } \\
75.34 \text { per cent. }\end{array}$ & $\begin{array}{l}\text { Found. } \\
75.37 \text { per cent. }\end{array}$ \\
\hline & $3 \cdot 14$ & $3 \cdot 42$ \\
\hline $0 \ldots \ldots$ & $21 \cdot 52$ & $21 \cdot 21$ \\
\hline
\end{tabular}

If a hot dilute solution of this substance in glacial acetic acid is slowly cooled, groups of small, orange-coloured crystals separate, just visible to the naked eye; these when collected, washed, and dried, present the appearance of beautiful, satiny, orange-coloured flakes. If hot saturated solutions are rapidly cooled, the substance is deposited as an orange-coloured gelatinous mass.

In the previous paper it was stated that this compound, $\mathrm{C}_{28} \mathrm{H}_{14} \mathrm{O}_{6}$, was converted into alizarin on fusion with potash. As it was important to be quite sure of this, the experiment was repeated with somewhat larger quantities, the decomposition being conducted in the following manner :-About 2 grams of $\mathrm{C}_{28} \mathrm{H}_{14} \mathrm{O}_{6}$ were heated with a very concentrated solution of caustic potash at $180^{\circ}$ for about 12 hours in a closed iron tube. The contents of the tube, which in appearance very much resembled an ordinary alizarin melt, were extracted with boiling water, the violet-coloured solution filtered from a small quantity of insoluble matter, and a little slaked lime added. The alizarate of lime thus precipitated was collected, well washed, suspended in water, decomposed with a little dilute hydrochloric acid, and the orange precipitate obtained was purified by recrystallisation from benzene. The product consisted of red needles melting at about $285^{\circ}$, and showing all the properties of alizarin. On analysis it gave the following numbers :-

0.1107 gram substance gave 0.0396 gram $\mathrm{H}_{2} \mathrm{O}$ and 0.2821 gram $\mathrm{CO}_{2}$.

\begin{tabular}{|c|c|c|}
\hline & $\begin{array}{l}\text { Theory. } \\
\mathrm{C}_{14} \mathrm{H}_{8} \mathrm{O}_{4}\end{array}$ & Found. \\
\hline C...... & 70.00 per cent. & 69.50 per cent. \\
\hline$H \ldots \ldots$ & $3 \cdot 33$ & $3 \cdot 97$ \\
\hline $0 \ldots \ldots$ & $26 \cdot 66$ & $26 \cdot 53$ \\
\hline
\end{tabular}

The filtrate from the alizarate of lime was of a reddish colour, with a green fluorescence; on treatment with hydrochloric acid, it deposited a very small quantity of a nearly white precipitate, which when washed on a filter changed to a dirty green. On fusion with potash and treatment of the fused mass with water, a solution was obtained having all the properties of potassic alizarate.

This substance is therefore intermediate between the red substance and alizarin; it is probably identical with a substance, $\mathrm{C}_{28} \mathrm{H}_{14} \mathrm{O}_{7}$, which 
will be described later on, under the heading "Action of Nitric Acid on $\mathrm{C}_{28} \mathrm{H}_{14} \mathrm{O}_{6}$." When fused with potash, $\mathrm{C}_{38} \mathrm{H}_{14} \mathrm{O}_{6}$ is probably first oxidised to $\mathrm{C}_{28} \mathrm{H}_{14} \mathrm{O}_{7}$, which then takes up the elements of water, and is converted into alizarin, thus :-

$$
\mathrm{C}_{28} \mathrm{H}_{14} \mathrm{O}_{7}+\mathrm{H}_{2} \mathrm{O}=2 \mathrm{C}_{14} \mathrm{H}_{8} \mathrm{O}_{4} \text {. }
$$

That such a change really takes place is all the more probable, from the fact that the substance $\mathrm{C}_{28} \mathrm{H}_{14} \mathrm{O}_{7}$, when fused with potash, also gives alizarin.

The residue from the fusion, insoluble in water, was crystallised from acetic acid, and thus obtained in orange needles, which were found to consist of unchanged $\mathrm{C}_{28} \mathrm{H}_{13} \mathrm{O}_{6}$.

$0 \cdot 1491$ gram substance gave 0.0470 gram $\mathrm{H}_{2} \mathrm{O}$ and 0.4097 gram $\mathrm{CO}_{2}$.

\begin{tabular}{|c|c|c|c|c|}
\hline \multicolumn{3}{|c|}{$\begin{array}{l}\text { Theory. } \\
\mathrm{C}_{29} \mathrm{H}_{14} \mathrm{O}_{6} .\end{array}$} & \multicolumn{2}{|c|}{$\begin{array}{l}\text { Found. } \\
75.01 \text { per cent }\end{array}$} \\
\hline $\mathrm{H} \ldots \ldots$ & $3 \cdot 14$ & $"$ & $3 \cdot 50$ & $"$ \\
\hline $0 \ldots \ldots$ & $21 \cdot 52$ & $"$ & $21 \cdot 49$ & $"$ \\
\hline
\end{tabular}

Cold Nordhausen sulphuric acid dissolves the red substance, forming a dirty green solntion, which in contact with the air absorbs moisture, and deposits the unchanged substance as a transparent jelly. When the solution in Nordhausen acid is heated to $190^{\circ}$, the colour gradually changes to a brownish-red, and if at the end of about half an hour the mixture is poured into water, it dissolves to a clear solution, which on cooling sets to an opaque jelly. All attempts to free this mixture from sulphuric acid by treatment with the carbonates of lead or barium failed, owing to the salts of the sulphonic acid being insoluble.

If the mixture of the sulphonic acid and sulphuric acid is neutralised with potash and slowly evaporated, the dark solution deposits a small quantity of a crystalline salt, which under the microscope is seen to consist of long needles; these when heated to $100^{\circ}$ fuse to a gummy mass. Fused with strong potash in an iron tube for some hours, and then decomposed with hydrochloric acid, a substance is obtained, which dyes mordanted cloth shades intermediate between those prodaced by anthrapurpurin and flavopurpurin.

\section{Action of Nitric Acid on $\mathrm{C}_{28} \mathrm{H}_{18} \mathrm{O}_{6}$.}

On gradually adding the red substance, $\mathrm{C}_{28} \mathrm{H}_{14} \mathrm{O}_{6}$, to cold fuming nitric acid of sp. gr. 1.5, it dissolves without evolution of red fumes, 
forming a bromine-coloured solution. In examining the product of this reaction, the mass was allowed to stand for a short time, and then diluted with water. This caused the precipitation of a yellowishwhite, amorphous substance, which was filtered off, well washed, and dried. It was then dissolved in a little hot aniline or nitrobenzene, filtered, and boiling alcohol added drop by drop to the hot solution until the mixture showed a tendency to become milky. On allowing this to cool slowly, minute crystals were deposited, which, after collecting, washing with alcohol, and drying at $110^{\circ}$, gave the following numbers on analysis :-

I. $0 \cdot 1366$ gram substance gave 0.0418 gram $\mathrm{H}_{2} \mathrm{O}$ and 0.3658 gram $\mathrm{CO}_{2}$.

II. $0 \cdot 1650$ gram substance gave 0.0505 gram $\mathrm{H}_{2} \mathrm{O}$ and $0 \cdot 4420$ gram $\mathrm{CO}_{2}$.

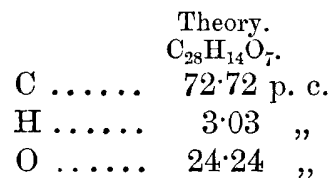

Found.

\begin{tabular}{|c|c|}
\hline I. & II. \\
\hline $73 \cdot 01$ & $73.05 \mathrm{p}$ \\
\hline $3 \cdot 40$ & $3 \cdot 40$ \\
\hline $23 \cdot 5$ & $23 . \check{5}$ \\
\hline
\end{tabular}

This substance has therefore the formula $\mathrm{C}_{28} \mathrm{H}_{14} \mathrm{O}_{7}$, being produced from the red substance $\mathrm{C}_{28} \mathrm{H}_{14} \mathrm{O}_{6}$ by the simple addition of oxygen, thus :-

$$
\mathrm{C}_{23} \mathrm{H}_{14} \mathrm{O}_{6}+\mathrm{O}=\mathrm{C}_{28} \mathrm{H}_{14} \mathrm{O}_{7} \text {. }
$$

Crystallised from a mixture of aniline or nitrobenzene and alcohol, this substance $\mathrm{C}_{28} \mathrm{H}_{18} \mathrm{O}_{7}$ appears under the microscope as groups of short, colourless needles. From hot acetone, however, in which it is only very slightly soluble, it can be obtained in larger crystals. It is slightly soluble in coal-tar naphtha, more soluble in acetic acid. When heated, it melts at a high temperature to a yellow liquid, which on cooling solidifies to a hard, crystalline mass. At higher temperatures it chars, only a very small quantity subliming in microscopic needles. $\mathrm{C}_{28} \mathrm{H}_{14} \mathrm{O}_{i}$ dissolves readily in hot aniline or nitrobenzene, and the solutions on cooling deposit small plates of a brownish colour. These substances, which are evidently additive compounds of $\mathrm{C}_{23} \mathrm{H}_{34} \mathrm{O}_{7}$ with aniline and nitrobenzene, have not as yet been analysed. They are readily obtained pure by adding cautiously to the hot solution in aniline or nitrobenzene about twice the volume of benzene. On cooling, the compound separates out in glistening plates. On boiling with alcohol, they are quickly split up into their constituents.

Boiled with zinc-dust and potash solution, $\mathrm{C}_{28} \mathrm{H}_{14} \mathrm{O}_{7}$ slowly dissolves, forming a reddish-brown solution, which on shaking with air instantaneously decolorises with precipitation of a white, gelatinous substance. 
The following reaction is characteristic of this substance:-If a trace be boiled with a strong solution of potash in methyl alcohol in a test-tube, it will gradually dissolve, with an olive-green coloration. On continued boiling, the solution becomes darker and darker coloured as the methyl alcohol evaporates, the green gradually changing to a beautiful brownish-pink. On adding water, a violet solution is obtained, which does not decolorise on shaking with air, and therefore possibly consists of potassic alizarate.

\section{Action of Nitric and Sulphuric Acids on $\mathrm{C}_{28} \mathrm{H}_{14} \mathrm{O}_{6}$.}

If $\mathrm{C}_{28} \mathrm{H}_{14} \mathrm{O}_{6}$ is treated with a mixture of nitric and sulphuric acids, a reaction quite different from the above takes place. In studying this, a small quantity of substance was boiled with a mixture of equal parts of nitric and sulphuric acids for a short time, the product poured into water, and the precipitate well washed and dried. In order to purify it, it was dissolved in hot acetic anhydride, the solution poured into an equal bulk of hot alcohol, and allowed to cool slowly. A beautiful yellow, crystalline powder was thus obtained, which on heating with potassium and then testing with ferrous and ferric chlorides, was found to contain a considerable amount of nitrogen. We have not as yet analysed this nitro-derivative, but its properties resemble very much those of the nitroanthraquinones except that it does not sublime when heated, but is alnost entirely decomposed, leaving a black residue. If heated with sulphuric acid, a violent reaction sets in, and on diluting the product with water, a red-violet precipitate is obtained, which dissolves in potash with a blue colour. When boiled with sodium sulphide, a brick-red amido-compound is obtained, resembling amidoanthraquinone, with which, however, it does not appear to be identical.

\section{Fusion of $\mathrm{C}_{28} \mathrm{H}_{14} \mathrm{O}_{\gamma}$ with Potash.}

In carrying out this experiment, the substance was heated in a closed iron tube with concentrated potash solution for 12 hours at $180^{\circ}$. The product was then boiled with water, filtered, a small quantity of lime added to the violet-blue filtrate, again filtered, and the residual violet powder washed with water and decomposed with bydrochloric acid.

The orange-coloured precipitate formed was washed with water, dried, and once or twice recrystallised from benzene. Red needles were thus obtained which melted at about $285^{\circ}$, and showed all the properties of alizarin. The analysis gave the following numbers:- 
0.1471 gram substance gave 0.0488 gram $\mathrm{H}_{2} \mathrm{O}$ and 0.3749 gram $\mathrm{CO}_{2}$.

\begin{tabular}{|c|c|c|}
\hline o & $\begin{array}{l}\text { Theory. } \\
\mathrm{C}_{14} \mathrm{H}_{8} \mathrm{O}_{4} \text {. } \\
70.00 \text { per cent. }\end{array}$ & $\begin{array}{l}\text { Found. } \\
69 \cdot 57 \text { per cent. }\end{array}$ \\
\hline & $3 \cdot 33$ & $3 \cdot 62$ \\
\hline$\ldots$ & $26 \cdot 66$ & $26 \cdot 81$ \\
\hline
\end{tabular}

The filtrate from the alizarate of lime was a red solution with a green fluorescence, which on acidifying gave a white precipitate, changing to green on washing. This substance, of which only a minute quantity was obtained, appeared to be unattacked $\mathrm{C}_{28} \mathrm{H}_{14} \mathrm{O}_{\gamma}$.

That portion of the product which was insoluble in water, after repeated recrystallisation from glacial acetic acid, appeared under the microscope as orange-red needles, giving with sulphuric acid a reddish-violet solution, and in all other respects showing the properties of the red substance $\mathrm{C}_{29} \mathrm{H}_{14} \mathrm{O}_{6}$. Dried at $120^{\circ}$, it gave the following results on analysis :-

0.0859 gram substance gave 0.0269 gram $\mathrm{H}_{2} \mathrm{O}$ and 0.2365 gram $\mathrm{CO}_{2}$.

\begin{tabular}{|c|c|c|}
\hline C....... & $\begin{array}{l}\text { Theory. } \\
\mathrm{C}_{28} \mathrm{H}_{14} \mathrm{O}_{6} \text {. } \\
75 \cdot 34 \text { per cent. }\end{array}$ & $\begin{array}{l}\text { Found. } \\
75.09 \text { per cent. }\end{array}$ \\
\hline 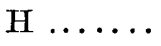 & $3 \cdot 14$ & $3 \cdot 48$ \\
\hline$\ldots$. & $21 \cdot 52$ & $21 \cdot 43$ \\
\hline
\end{tabular}

Two distinct reactions therefore take place when $\mathrm{C}_{28} \mathrm{H}_{11} \mathrm{O}_{\tau}$ is fused with potash.

In the first place the elements of water are taken up, 1 mol. of $\mathrm{C}_{28} \mathrm{H}_{14} \mathrm{O}_{7}$ splitting up into 2 mols. of alizarin, thus :-

$$
\mathrm{C}_{28} \mathrm{H}_{14} \mathrm{O}_{7}+\mathrm{H}_{2} \mathrm{O}=2 \mathrm{C}_{14} \mathrm{H}_{8} \mathrm{O}_{4} \text {, }
$$

whereas at the same time a certain amount of reduction takes place, some of the $\mathrm{C}_{28} \mathrm{H}_{14} \mathrm{O}_{7}$ being reduced to the original red substance, thus:-

$$
\begin{aligned}
& \mathrm{C}_{28} \mathrm{H}_{14} \mathrm{O}_{7}+\mathrm{H}_{2}=\mathrm{C}_{28} \mathrm{H}_{14} \mathrm{O}_{6}+\mathrm{H}_{2} \mathrm{O} \text {. } \\
& \text { Action of Chromic Acid on } \mathrm{C}_{28} \mathrm{H}_{14} \mathrm{O}_{7} \text {. }
\end{aligned}
$$

In the first paper on these anthraquinone-derivatives (loc. cit., p. 683), we showed that when the red substance $\mathrm{C}_{25} \mathrm{H}_{14} \mathrm{O}_{6}$ is oxidised with chromic acid in acetic solution it is converted into a white sub stance of the formula $\mathrm{C}_{14} \mathrm{H}_{6} \mathrm{O}_{4}$, thus :-

$$
\mathrm{C}_{28} \mathrm{H}_{14} \mathrm{O}_{6}+\mathrm{O}_{3}=2 \mathrm{C}_{14} \mathrm{H}_{6} \mathrm{O}_{4}+\mathrm{H}_{2} \mathrm{O} \text {. }
$$


On considering the results just described, it appeared likely that the substance $\mathrm{C}_{28} \mathrm{H}_{14} \mathrm{O}_{7}$ was really the first product of the action of oxidising agents on $\mathrm{C}_{28} \mathrm{H}_{14} \mathrm{O}_{6}$, and that this, therefore, on further oxidation should yield the same substance, $\mathrm{C}_{14} \mathrm{H}_{6} \mathrm{O}_{4}$, as is obtained direct by the action of chromic acid on $\mathrm{C}_{z 8} \mathrm{H}_{14} \mathrm{O}_{6}$. In order to decide this point, a small quantity of the substance $\mathrm{C}_{28} \mathrm{H}_{14} \mathrm{O}_{7}$ was dissolved in hot glacial acetic acid, and treated with chromic acia until the violent reaction which set in at first had subsided. On allowing the green solution to cool, a white, crystalline powder was deposited. This was collected, washed, dried, and several times recrystallised from glacial acetic acid.

In this way the product was easily separated into two portions, one of which was considerably more soluble in acetic acid than the other.

The less soluble portion on analysis gave the following numbers:-

0.1583 gram substance gave 0.0385 gram $\mathrm{H}_{2} \mathrm{O}$ and 0.4100 gram $\mathrm{CO}_{2}$.

\begin{tabular}{|c|c|c|}
\hline C. & $\begin{array}{l}\text { Theory. } \\
\mathrm{C}_{14} \mathrm{H}_{6} \mathrm{O}_{4} \text {. } \\
70.59 \text { per cent. }\end{array}$ & $\begin{array}{l}\text { Found. } \\
70.63 \text { per cent. }\end{array}$ \\
\hline$H \ldots$ & $2.52 \quad$ & $2 \cdot 70$ \\
\hline O....... & $26 \cdot 89$ & $26 \cdot 67$ \\
\hline
\end{tabular}

The substance therefore has the formula $\mathrm{C}_{14} \mathrm{H}_{6} \mathrm{O}_{4}$, and a careful comparison showed that it is without doubt identical with that produced by the direct oxidation of the red substance $\mathrm{C}_{28} \mathrm{H}_{14} \mathrm{O}_{6}$ with chromic acid. Attempts to produce the substance $\mathrm{C}_{28} \mathrm{H}_{14} \mathrm{O}_{7}$ by cautious oxidation of $\mathrm{C}_{28} \mathrm{H}_{14} \mathrm{O}_{6}$ with chromic acid were unsuccessful, the reaction in all cases going as far as the formation of the compound $\mathrm{C}_{14} \mathrm{H}_{6} \mathrm{O}_{4}$.

The more soluble substance obtained in the above oxidation was found on examination to consist of unchanged substance, as the following analysis shows :-

0.1699 gram substance gave 0.0490 gram $\mathrm{H}_{2} \mathrm{O}$ and 0.4520 gram $\mathrm{CO}_{2}$.

\begin{tabular}{|c|c|c|}
\hline ב........ & $\begin{array}{l}\text { Theory. } \\
\mathrm{C}_{28} \mathrm{H}_{14} \mathrm{O}_{7 \cdot} \\
72 \cdot 72 \text { per cent. }\end{array}$ & $\begin{array}{l}\text { Found. } \\
72.51 \text { per cent. }\end{array}$ \\
\hline $1 \ldots .$. & 3.03 & $3 \cdot 20 \quad$ \\
\hline$\ldots$ & $24 \cdot 25$ & $24 \cdot 29$ \\
\hline
\end{tabular}

Action of Hydriodic Acid on $\mathrm{C}_{28} \mathrm{H}_{14} \mathrm{O}_{i}$.

Experiments were next made with the object of removing some of the oxygen-atoms from the molecule $\mathrm{C}_{28} \mathrm{H}_{14} \mathrm{O}_{0}$ in the hope of thus 
obtaining some well-known compound, the formation of which might throw additional light on the nature of the red substance.

If $\mathrm{C}_{28} \mathrm{H}_{14} \mathrm{O}_{6}$ is suspended in hot glacial acetic acid, and fuming aqueous hydriodic acid added drop by drop, the crystals rapidly dissolve, forming a deep red solution which contains free iodine; this is filtered and poured into water, when a lemon-yellow precipitate is deposited, which is collected, well washed, dried, and purified by recrystallisation from a mixture of hot aniline and alcohol; on cooling, it is deposited as a yellow, crystalline powder. Two different samples dried at $110^{\circ}$ were analysed with the following results :-

I. $0 \cdot 1457$ gram substance gave 0.0470 gram $\mathrm{H}_{2} \mathrm{O}$ and 0.4160 gram $\mathrm{CO}_{2}$.

II. 0.0659 gram substance gave 0.0212 gram $\mathrm{H}_{2} \mathrm{O}$ and $0 \cdot 1880$ gram $\mathrm{CO}_{2}$.

\begin{tabular}{|c|c|c|c|c|}
\hline \multirow[b]{3}{*}{ C..... } & \multicolumn{2}{|c|}{ Found. } & \multicolumn{2}{|c|}{ Theory. } \\
\hline & I. & II. & $\overparen{\mathrm{C}_{28} \mathrm{H}_{14} \mathrm{O}_{5}}$. & $\overline{\mathrm{C}_{28} \mathrm{H}_{16}} \mathrm{O}_{5}$. \\
\hline & $77 \cdot 86$ & $77 \cdot 80$ p. c. & $78 \cdot 14$ & 77.77 p. c. \\
\hline $\mathrm{H}$ & 3.58 & 3.57, & $3 \cdot 26$ & $3 \cdot 70$ \\
\hline $0 \ldots \ldots$ & $18 \cdot 56$ & 18.53, & $18 \cdot 60$ & 18.52 \\
\hline
\end{tabular}

The numbers obtained agree, therefore, better with the formula $\mathrm{C}_{28} \mathrm{H}_{14} \mathrm{O}_{5}$ than with $\mathrm{C}_{28} \mathrm{H}_{16} \mathrm{O}_{5}$, and it is probable that this new compound is formed from the red substance simply by elimination of oxygen, thus :-

$$
\mathrm{C}_{28} \mathrm{H}_{14} \mathrm{O}_{6}+\mathrm{H}_{2}=\mathrm{C}_{28} \mathrm{H}_{14} \mathrm{O}_{5}+\mathrm{H}_{2} \mathrm{O} \text {. }
$$

This substance, $\mathrm{C}_{28} \mathrm{H}_{14} \mathrm{O}_{5}$, which is insoluble in aqueous potash, dissolves in a strong, hot solution of potash in methyl alcohol, with an intense orange-brown colour which on long boiling does not change. If the alcohol is evaporated, the colour becomes intenser as the solution becomes stronger, until at last a dark-brown residue is left; this dissolves in water with an orange-red colour, which, however, almost disappears on shaking with air.

When boiled with zinc-dust and potash, $\mathrm{C}_{28} \mathrm{H}_{14} \mathrm{O}_{5}$ gives scarcely any coloration, but it dissolves in concentrated sulphuric acid, forming an intense reddish-brown solution.

The ease with which the red substance $\mathrm{C}_{28} \mathrm{H}_{14} \mathrm{O}_{6}$ loses 1 atom of oxygen, and is reduced to $\mathrm{C}_{28} \mathrm{H}_{14} \mathrm{O}_{5}$, led us to think that it would be interesting to study the further action of hydriodic acid on this substance. For this purpose, a mixture of 0.5 gram of the pure red substance, 5 grams of fuming hydriodic acid, and 5 grams of glacial acetic acid were heated in a sealed tube for about half an hour to $160^{\circ}$. The dark-red liquid thus obtained was gently evaporated to get rid of most of the acetic acid, the residue freed from iodine by 
boiling with dilute aqueous sulphurous acid. The precipitate, which separated on cooling, was collected, filtered, washed with water, and dried on a porous plate. On extracting the product with alcohol, nearly the whole dissolved, leaving a small quantity of a yellow substance behind. This residue, after careful drying and sublimation in a test-tube, formed microscopic yellow needles melting at about $260-265^{\circ}$, and which on boiling with potash solution and zinc-dust gave a red solution becoming colourless again on shaking with air. This substance was, therefore, probably anthraquinone.

The alcoholic solution on evaporation deposited a considerable quantity of a somewhat sticky yellow substance, which, especially when boiled with water, possessed in a marked degree the peculiar odour of dihydroanthracene. In order to determine whether the reduction really had gone as far as this, the crude substance was distilled in a test-tube, the solid distillate washed with a little alcohol, and then recrystallised from this solvent. In this way, small crystals were obtained which melted at $104-106^{\circ}$, and otherwise showed all the properties of dibydroanthracene.

\section{Action of Sulphuric Acid on $\mathrm{C}_{28} \mathrm{H}_{14} \mathrm{O}_{7}$.}

In studying this action, a small quantity of the substance was heated with fuming sulphuric acid at $180^{\circ}$. The reddish-brown solution first formed became gradually darker and eventnally, after 20 minutes' heating, of a hluish-red colour. At this stage, the decomposition was evidently complete, the product dissolving completely in water, showing that a sulphonic acid had been formed. On adding acetic acid to the strong hot solution, and allowing it to cool, a small quantity of a crystalline precipitate separated. It was, however, found impracticable to purify the sulphonic acid by this method, as it was too soluble in acetic acid to admit of sufficient washing. The mixture of the sulphonic acid and sulphuric acid dissolved in water forming a greenish solution, with which lead or barium carbonate yielded insoluble compounds only.

In order, if possible, to determine the nature of the sulphonic acid thus formed, resort was had to fusion with potash. The solution was mixed with a considerable excess of concentrated aqueous potash, and heated in closed iron tubes at $180^{\circ}$ for about 12 hours. The product dissolved in water, forming a red-violet solution, and on the addition of acids a brownish-yellow precipitate was thrown down, which was collected and well washed with water. This substance dyed mordanted cloth shades intermediate between those given by anthrapurpurin and flavopurpurin, and, therefore, probably consists of a mixture of these two substances. 


\section{Fusion of $\mathrm{C}_{14} \mathrm{H}_{6} \mathrm{O}_{4}$ with Potash.}

'This substance, the preparation of which was given in the previous paper (loc. cit., p. 683), is formed by the oxidation of the red substance, $\mathrm{C}_{28} \mathrm{H}_{14} \mathrm{O}_{6}$, with chromic acid in acetic acid solution. Considering the interesting constitution previonsly assigned to this substance and its mode of formation from the red substance, it was thought that valuable results might be obtained from the further study of its properties. The first decomposition which was studied was the action of caustic potash at high temperatures on this substance. Two grams of pure $\mathrm{C}_{14} \mathrm{H}_{6} \mathrm{O}_{7}$ were heated with concentrated potash solution for about 12 bours at $180^{\circ}$, the dark-coloured product extracted with boiling water and filtered. A small quantity of lime was then added to the bluish-violet filtrate, the lime compound thus precipitated, collected, washed with water, and decomposed with dilute hydrochloric acid. This caused the precipitation of an orange-red compound, which after collecting, washing with water, drying and recrystallising once or twice from benzene, was obtained in long red needles; it melts at about $285^{\circ}$, and possesses all the properties of alizarin.

The analysis gave the following numbers:-

0.1175 gram substance gave 0.0391 gram $\mathrm{H}_{2} \mathrm{O}$ and 0.1175 gram $\mathrm{CO}_{2}$.

\begin{tabular}{|c|c|c|}
\hline C. . & $\begin{array}{l}\text { Theory. } \\
\mathrm{C}_{14} \mathrm{H}_{8} \mathrm{O}_{4} \text {. } \\
70 \cdot 00 \text { per cent. }\end{array}$ & $\begin{array}{l}\text { Found. } \\
69.98 \text { per cent. }\end{array}$ \\
\hline $\mathrm{H}$. & $3 \cdot 33$ & $3 \cdot 69$ \\
\hline O... & $20 \cdot 67$ & $20 \cdot 43$ \\
\hline
\end{tabular}

The portion of the product insoluble in water obtained during the fusion of $\mathrm{C}_{11} \mathrm{H}_{6} \mathrm{O}_{2}$ with potash, was extracted several times with glacial acetic acid, and boiling water added to the filtrate. On cooling, long orange-coloured needles were deposited which on analysis gave numbers corresponding with the formula $\mathrm{C}_{14} \mathrm{H}_{8} \mathrm{O}_{2}$.

I. 0.1235 gram substance gave 0.0463 gram $\mathrm{H}_{2} \mathrm{O}$ and 0.3648 gram $\mathrm{CO}_{2}$.

II. 0.1285 gram substance gave 0.0466 gram $\mathrm{H}_{2} \mathrm{O}$ and 0.3800 gram $\mathrm{CO}_{2}$.

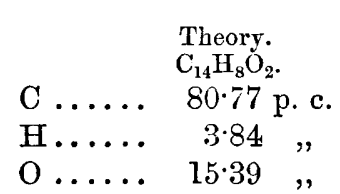

Found.

\begin{tabular}{|c|c|}
\hline \multicolumn{2}{|c|}{ Found. } \\
\hline I. & II. \\
\hline 0.60 & $80 \cdot 65$ p.c. \\
\hline $4 \cdot 17$ & $4.03 \quad$, \\
\hline $15 \cdot 23$ & $15 \cdot 32$ \\
\hline
\end{tabular}

This compound, obtained by the fusion of $\mathrm{C}_{14} \mathrm{H}_{6} \mathrm{O}_{4}$ with potash, did not at all resemble anthraquinone outwardly, as, however often it was 
recrystallised, it was always deposited in flat, silky needles of an orange colour. It melted, however, at $275^{\circ}$, the melting point of anthraquinone, and when heated strongly it sublimed much in the same way as ordinary anthraquinone, so that there can be no doubt as to its identity with that substance.

The action of caustic potash on $\mathrm{C}_{14} \mathrm{H}_{6} \mathrm{O}_{4}$ appears, therefore, to be entirely a reducing action, alizarin and anthraquinone being formed according to the equations-

$$
\begin{aligned}
& \text { I. } \mathrm{C}_{14} \mathrm{H}_{6} \mathrm{O}_{4}+\mathrm{H}_{2}=\mathrm{C}_{14} \mathrm{H}_{8} \mathrm{O}_{4}, \\
& \text { II. } \mathrm{C}_{14} \mathrm{H}_{6} \mathrm{O}_{4}+3 \mathrm{H}_{2}=\mathrm{C}_{14} \mathrm{H}_{8} \mathrm{O}_{2}+2 \mathrm{H}_{2} \mathrm{O} .
\end{aligned}
$$

\section{Action of Sulphuric Acid on $\mathrm{C}_{14} \mathrm{H}_{6} \mathrm{O}_{4}$.}

In studying this reaction, the substance $\mathrm{C}_{14} \mathrm{H}_{6} \mathrm{O}_{4}$ was heated with three or four parts of Nordhansen sulphuric acid at $200^{\circ}$ until a sample taken out dissolved entirely in water. As soon as this was found to be the case, the product was poured into glacial acetic acid drop by drop, the whole being constantly stirred during the operation. This caused the separation of a white substance which, when examined under the microscope, was seen to consist of a mass of small crystals. When the precipitation was complete, about twice the bulk of glacial acetic acid was added, the mixture thrown on a filter, washed with glacial acetic acid till free from sulphuric acid, and then well drained. The product was dissolved in a little water, and alcoholic soda added to the solution until the white crystalline salt thus formed had been completely precipitated. After collecting, well washing with alcohol and drying at $100^{\circ}$, this salt gave the following numbers on analysis :-

0.1963 gram substance gave 0.0333 gram $\mathrm{H}_{2} \mathrm{O}$.

0.3540 gram $\mathrm{CO}_{2}$.

\begin{tabular}{|c|c|c|c|c|}
\hline \multicolumn{3}{|c|}{$\begin{array}{c}\text { Theory. } \\
\mathrm{C}_{14} \mathrm{H}_{5} \mathrm{O}_{4} \cdot \mathrm{SO}_{3} \mathrm{Na}\end{array}$} & \multirow{2}{*}{\multicolumn{2}{|c|}{$\begin{array}{l}\text { Found. } \\
49^{\circ} \cdot 18 \text { per cent. }\end{array}$}} \\
\hline C....... & $49 \cdot 41$ & cent. & & \\
\hline $\mathrm{H} \ldots \ldots$. & $1 \cdot 47$ & " & $1 \cdot 88$ & $"$ \\
\hline $\mathrm{Na} \ldots .$. & $6 \cdot 76$ & $"$ & $6 \cdot 84$ & $"$ \\
\hline $0 . . . .$. & $32 \cdot 95$ & $"$ & - & \\
\hline s....... & $9 \cdot 41$ & $"$ & - & \\
\hline
\end{tabular}

0.0415 gram $\mathrm{Na}_{2} \mathrm{SO}_{4}$.

Solutions of this salt give precipitates with salts of copper, lead, barium, and other metals. On fusion with potash, this sulphonic acid yields a reddish-violet solution which, on addition of acids, deposits a yellow precipitate. This after being collected and washed 
with water, was found to dye mordanted cloths shades vory closely resembling those produced by flavopurpurin. As the substance also gave the same absorption-bands as flavopurpurin there can be no doubt of its identity with this substance.

In order to examine more completely the action of sulphuric acid on $\mathrm{C}_{14} \mathrm{H}_{6} \mathrm{O}_{4}$, the acetic acid filtrate from the precipitated sulphonic acid was next experimented on, thus :-After distilling off the acetic acid, the residue was dissolved in potash, fused with an excess of strong potash solution in an iron tabe, and the product isolated in the usual way. The yellowish-brown flocculent precipitate thus obtained dyed mordanted cloth with shades slightly yellower than, but otherwise exactly similar to, those produced by anthrapurpurin, and a careful examination of the substance showed that it agreed with this compound in all its reactions. By the action of Nordhausen sulphuric acid on $\mathrm{C}_{14} \mathrm{H}_{6} \mathrm{O}_{4}$, it would appear, therefore, that two suiphonic acids are formed, of which one is insoluble and the other soluble in glacial acetic acid. On fusion with potash, the former yields flavopurpurin and the latter anthrapurpurin.

\section{Theoretical Remarks.}

On considering the results described in the body of this paper, it appears very doubtful whether the red substance $\mathrm{C}_{28} \mathrm{H}_{14} \mathrm{O}_{6}$ can have the formula first assigned to it (loc. cit., p. 684), namely-

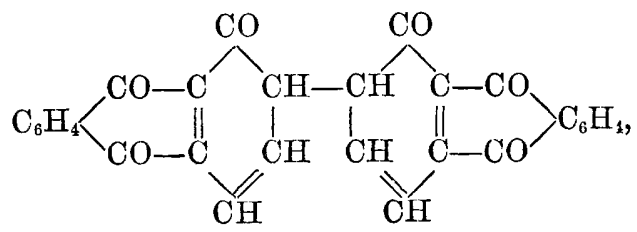

as this formula does not in any way explain the formation of the oxidation compound $\mathrm{C}_{28} \mathrm{H}_{14} \mathrm{O}_{7}$, or the decomposition into alizarin by fusion with potash. A reaction of this kind would involve the severing of the two anthraquinone molecules, which would hardly take place so easily if they were joined simply carbon to carbon, as shown above.

In order to be able to explain the formation of its varions derivatives, it is necessary to suppose that the two anthraquinone molecules are linked together in a much more feeble way, as for instance with the intervention of an oxygen-atom.

The most probable formula for the red substance $\mathrm{C}_{28} \mathrm{H}_{14} \mathrm{O}_{6}$, and one which would explain all its decompositions, would be- 


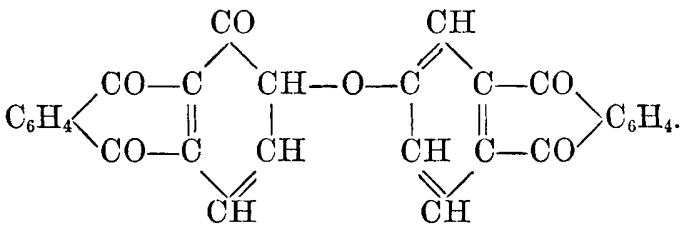

By the action of nitric acid this substance is converted into $\mathrm{C}_{28} \mathrm{H}_{14} \mathrm{O}_{\overline{7}}$, which would be represented by the formula-

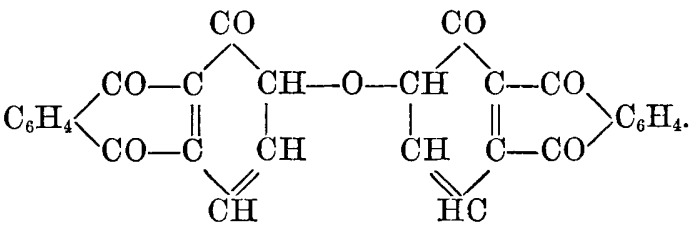

On further oxidation this substance is converted into 2 mols. of $\mathrm{C}_{14} \mathrm{H}_{6} \mathrm{O}_{4}$, a change which is easily understood if we assume that the latter substance has the constitution which was previously assigned to it; that is-

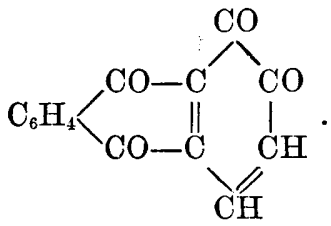

There is every reason to believe that this substance has the simple formula $\mathrm{C}_{14} \mathrm{H}_{6} \mathrm{O}_{4}$, and not the double formula $\mathrm{C}_{28} \mathrm{H}_{12} \mathrm{O}_{8}$. The comparatively low melting point of this substance (about $300^{\circ}$ ), and the fact that it sublimes easily and completely when heated, almost exclnde the possibility of its having the double molecular weight $\mathrm{C}_{28} \mathrm{H}_{12} \mathrm{O}_{8}$.

The constitutional formula given above for this substance easily explains the reduction to alizarin and anthraquinone by the action of potash at a high temperature.

Lastly, the substance $\mathrm{C}_{28} \mathrm{H}_{14} \mathrm{O}_{5}$, produced by the action of hydriodic acid on $\mathrm{C}_{28} \mathrm{H}_{14} \mathrm{O}_{6}$, would be represented by the formula-

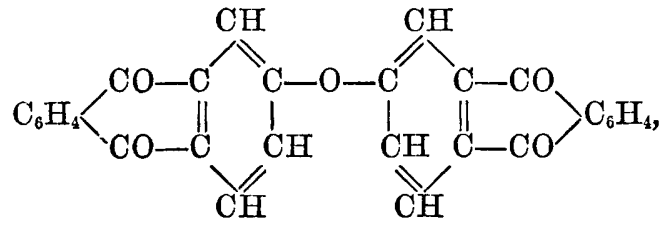


844 TURNER: THE INFLUENCE OF SILICON

which in its turn would easily explain the formation of anthraquinone and dihydroanthracene by the further reducing action of hydriodic acid. 